\title{
CO-DEPENDENCY IN INTIMATE RELATIONSHIP-A LEARNED BEHAVIOUR
}

\author{
Prof. PhD. Claudia VLAICU ${ }^{1}$, PhD. Candidate Felicia Aurica HAIDU ${ }^{2}$, \\ "Valahia" University of Târgoviște, ROMANIA", \\ Candidate for a doctor's degree in Psychology, Chisinau, \\ REPUBLIC OF MOLDAVIA ${ }^{2}$, \\ Email: vlaicu.claudia@gmail.com
}

\begin{abstract}
The present paper is structured as a theoretical article, explaining the paradigm codependency in intimate relationship, analysing the symptoms of co-dependency and suggesting cognitive-behaviour therapeutic ways of healing from co-dependency.

The psychological premise of this approach is that co-dependency is a learned behaviour. The early life scenarios of co-dependents encompass actions of our parents displaying problems with boundaries, and unhealthy ways to communicate, so the most likely learned these behaviours and brought them into their intimate relationships. Children who grow up with emotionally unavailable parents also are at risk for being co-dependent. They often find themselves in relationships where their partner is emotionally unavailable, yet they stay in the hopes that they can change the person. The list of symptoms of co-dependency and being in a codependent relationship includes: low-self-esteem, reactivity, caretaking, control, dysfunctional communication, obsessions, dependency, denial, problems with intimacy and painful emotions.
\end{abstract}

Keywords: co-dependency; cognitive-behaviour therapy; relationship; dependency; self;

\section{INTRODUCTION}

The term co-dependency has been around for decades and although it was first applied to alcoholics, in time, researchers found out that a person who was raised in a dysfunctional family or had an ill parent, could also be co-dependent.

Researchers also found that co-dependent symptoms got worse if left untreated. The present paper refers to co-dependency in intimate relationship as a learned behaviour. It also presents the symptoms of co-dependency and suggests means of treating it.

\section{THEORETICAL BACKGROUND}

2.1. The co-dependency construct has its genesis traced back to 1784 , when one of the signers of the Declaration of Independence, Dr. Benjamin Rush, first described habitual drunkenness as a disease. The construct of co-dependency evolved from the chemical dependency field in the treatment of families of alcoholics. This term has become popular among mental health professionals as well as the general public since its inception at the end 1970s.

Later on, the family systems movement also contributed to the formation of the codependency construct. Alcoholics 'drinking behaviour had an impact on the entire family system as well as its individual members.[8]

Although originally co-dependency described an unhealthy pattern of coping adopted by someone who was closely involved with a chemically dependent person, the label "co- 
dependent" was gradually preferred for its greater inclusiveness. Thus, experts in the treatment field started realizing that other problems, such as overeating and gambling, paralleled the illness of alcoholism, and could affect family members in a similar fashion. Since the early 1980s, the term has been expanded and popularized so that it has surpassed its situational boundaries. Consequently, a co-dependent person has become one who has a relationship, personally or professionally, with a "troubled, needy, or dependent person.[1]

Among co-dependency theorists, similar definitional ambiguity can be seen. More and more, the co-dependency label, in its definitional ambiguity and societal endorsement, seems almost impossible to reject.

To be labelled co-dependent is increasingly to be judged as sick. The industry rewards people for calling themselves helpless, childish, and addicted, and punishes people who call themselves healthy (they are simply "in denial").[5]

On the other hand, although alcoholism is a societal problem, it is the co-dependent individuals who live with the alcoholic who often appear to carry the blame for the damage caused. Therefore, it can be expected that a person who embraces the co-dependency label may experience deleterious psychological consequences.

In 1989, experts at a National Conference on Co-dependency arrived at a consensual definition: "A pattern of painful dependency on compulsive behaviours and on approval from others in an attempt to find safety, self-worth and identity."

Co-dependents have been described as having a "lost self." John Bradshaw (2010) defined co-dependency as "a loss of one's inner reality and an addiction to outer reality."[4]. Darlene Lancer (2015) refers to a co-dependent "as a person who can't function from his or her innate self and instead organizes thinking and behavior around a substance, process, or other person(s)." [2] The disorder exists in the person whether or not he or she is in a relationship.

Co-dependents become dependent on other people in unhealthy ways, even though they might do fine on their own. The degree of co-dependency varies on a spectrum. Some experts consider co-dependency a disease and addiction because, like alcoholism, the behaviour is compulsive and worsens over time if untreated. It progresses through stages of degeneration and regeneration during its decline and recovery.[2]

\subsection{Co-dependency as a learned behaviour}

Co-dependency is connected not just to alcoholism or chemical dependence in families but to various types of chronic family stressors. They may be predictors of codependency. In addition to parental chemical dependency, other family stressors may include ineffective parenting styles, parental abuse, as well as parental mental and physical health. In their works M. Crothers and L.W. Warren studied parental chemical dependency and the results of their study indicate that parental chemical dependency, maternal and paternal codependency as well as maternal coercion are significant predictors of co-dependency. The results also indicated that the co-dependency occurred not only in the families of drug addicts, alcoholics, abuse problems but in those who have been physically or sexually abused. [7]

The effects of much more serious childhood experiences such as abuse have been explored more recently by Reyome and Ward (2007). They investigated the relationship between co-dependency and reported child abuse and neglect. [7]

Still attempting to establish a relationship between co-dependency and family of origin, other researchers (Ancel and Kabakci, 2009) explored the relationship of co- 
dependency with individuals' attachment styles and perceived family dysfunction in childhood. Students with high levels of reported co-dependency presented more attachmentrelated anxiety and reported more family problems in childhood. These results suggested that anxiously related people may engage in dysfunctional relationships in an attempt to gain a sense of value and self-worth. Other types of research findings on the issue contended that family stress, independently from parental alcoholism, may be associated with the onset of co-dependency in adults (Fuller and Warner,2000; Crothers and Warren, 1996). The majority of the studies on the topic suggested an association between co-dependency and reported difficulties in family of origin (Ancel and Kabakci 2009; Reymond and Ward 2007; Fuller and Warner's 2000; Crothers and Warren's 1996). [6]

However, two studies (Knudsun and Terrell 2012; Cullen and Carr, 1999) suggested that these difficulties may be related to learning behaviours associated with family conflict, not necessarily parental substance misuse; however, not all statistical associations were based on validated scales. [6]

Studies suggested a range of difficulties in families of origin associated with parental dysfunction (compulsivity, co-dependency and substance dependence), negative parental styles (coercion, control, non-nurturance), child abuse and neglect, and interpersonal conflicts in the family of origin.

Cognitive-behaviour therapies on co-dependency imply the interviewing part encompassing the client's perceptions and recollection of their family experiences. People who identify themselves as having co-dependent characteristics usually frame their family of origin as responsible in some way for their difficulties and selectively report problems in early relationships (or indeed recall higher levels of childhood trauma). Therefore, they try to identify and analyse in the therapeutic process specific factors which may or may not increase the risk of co-dependency understood as a psychological problem.

The psychological premise that this type of therapies use is that the family patterns of thinking and behaviour are unconsciously copied by the child and he or she uses them later on in adult relationships in the same form or in a different one. More specifically, what we see as the actions of our parents when we are children ( our mother or father having a problem with boundaries, for instance or was always the martyr, could never say 'no' to people, and had unhealthy ways to communicate) we most likely learned these behaviours and brought them into our intimate relationships.

Children who grow up with emotionally unavailable parents also are at risk for being co-dependent. They often find themselves in relationships where their partner is emotionally unavailable, yet they stay in the hopes that they can change the person. No matter what happens, they won't stop hoping that one day things will be good. [3]

\subsection{Symptoms of Co-dependency}

The following is a list of symptoms of co-dependency and being in a co-dependent relationship [2]:

Low self-esteem (the person feels that he/she is not good enough or comparing himself/herself to others; what such persons actually feel is that he is unlovable or inadequate; feelings of shame and guilt and perfectionism often go along with low selfesteem)

- People-pleasing (co-dependents usually don't think they have a choice. Saying "No" causes them anxiety. Because some co-dependents have a hard time saying "No" to 
anyone, they go out of their way and sacrifice their own needs to accommodate other people)

- Poor boundaries. ( They have blurry or weak boundaries. They feel responsible for other people's feelings and problems or blame their own on someone else.)

- Reactivity.(A consequence of poor boundaries is that react to everyone's thoughts and feelings. )

- Caretaking.(Another effect of poor boundaries is that if someone else has a problem, the want to help them to the point that they give up themselves)

- Control.(Control helps co-dependents feel safe and secure. Everyone needs some control over events in their life. For co-dependents, control limits their ability to take risks and share their feelings)

- Dysfunctional communication. (Co-dependents have trouble when it comes to communicating their thoughts, feelings and needs)

- .Obsessions (Due to their anxieties and fear, co-dependents have a tendency to spend their time thinking about other people or relationships)

- Dependency (Co-dependents need other people to like them to feel okay about themselves. They're afraid of being rejected or abandoned, even if they can function on their own)

- Denial. (this is one major problem for co-dependends, that they're in denial about it; not only about facing their problem, but also about their feelings and needs. Often, they don't know what they're feeling and are instead focused on what others are feeling.)

- Problems with intimacy.(they often experience sexual dysfunction and find it very difficult to be open and close with someone in an intimate relationship. )

- Painful emotions.(Co-depends experience stress and painful and complex emotions: shame and low self-esteem, fear about being judged, rejected or abandoned; feeling trapped by being close or being alone, anger and resentment, depression, hopelessness, and despair. )

\section{ARGUMENT OF THE PAPER}

Our perspective relates the phenomenon of co-dependency to the formation of personality regarding it as arising as a symbiotic phase of development in early childhood and interrupting separation-individuation phase, which in turn has a profound influence on subsequent relationships. They form relationships that are not healthy, looking to 'fix' the other person.

The argument of the paper revolves around the psychodynamic view of early child development. Frequently, the primary caretaker is the mother; it may be the father, grandparent, or other relative or combination of people. When infant parenting is inadequate, it likely reflects dysfunction in the whole family, which further damages the growing child's self.

A person with co-dependent tendencies may find themselves in an intimate relationship with a person who has addiction issues that cause them to be emotionally unavailable. Their partner or they themselves may be workaholics or develop some other compulsive behaviour to avoid the feeling of emptiness in the relationship. This is easier in the short term than looking within and dealing with emotions. 


\section{ARGUMENTS TO SUPPORT THE THESIS}

Children are born vulnerable, full of needs and dependent on their caretakers for everything. To grow, they need touch as much as food plus attention, empathy, nurturing, and security. Starting at four to six months and continuing onward, babies must confidently achieve separation from their mothers and establish their own boundaries. The key to the separationindividuation process and the formation of a healthy Self is the mother's ability to mirror the child's feelings. She does this by empathically and intuitively matching her responses to her child's needs. Generally, deficient or inadequate mirroring reflects a mother's incomplete Self, which is how co-dependency becomes generational. The mother's defective mirroring may be caused by her: illness, grief, stress due to external events, mental or emotional deficits, including depression and narcissism, rigid boundaries, mother's inability to empathize, weak boundaries.

Weak boundaries are typical of codependents. With inadequate mirroring, children learn that their needs, feelings, and thoughts are unimportant, wrong, and shameful Codependent mothers may unconsciously fail to support their children's emerging drive for independence.

On the other hand, there may be family problems and crises, such as a member's absence, illness, or addiction, that never get talked about. Parents think that if they try to act normal and pretend the problem doesn't exist, maybe it will go away, and children won't notice or be harmed; the children adopt behaviors to relieve the family tension, which vary depending upon the child's personality and birth order.

\section{ARGUMENTS TO ARGUE THE THESIS}

Critics of co-dependency tend to see it as merely a social or cultural phenomenon; the basis idea is that co-dependent mothers may unconsciously fail to support their children in their emerging drive for independence. They state that it is natural to need and depend upon others. This aspect of relationships when you depend upon a partner doesn't need to be changed. They claim that you only really thrive in an intimate relationship and believe that the co-dependency movement has hurt people and relationships by encouraging too much independence, and a false-sense of self-sufficiency, which can pose health risks associated with isolation. In Romania, the orthodox dogma regarding family relationships, for instance, encourages the preservation of traditional family customs, where men should be the ones who work and women should stay at home raising children. Being financial dependent upon the husband, the wife is compelled to agree to the partner's overall vision of the world, family and relationship.

Other directions of analysis of the construct of co-dependency tend to regard it as being merely an outgrowth of Western ideals of individualism and independence, which have harmed people by diminishing their need for connection to others. Feminists also criticized the concept of codependency as sexist and pejorative against women, stating that women are traditionally nurturers and historically have been in a non-dominant role due to economic, political, and cultural reasons. Investment in their relationships and partner isn't a disorder, but has been necessary for self-preservation. Still others quarrel with Twelve Step programs in general, saying that they promote dependency on a group and a victim mentality.[2]

\subsection{Cognitive-Behavioural interventions in the treatment of Co-dependency}

Among the interventions that proved their efficacy to treat co-dependency, the cognitive-behavioural therapies gained their rank both in Western cultures and in European ones. In cognitive treatment of co-dependency the accent is placed on changing the person's 
cognition about him and others and making new cognitions; it is, therefore, believed that improvement of cognition can change and improve co-dependent behaviours.

Since our theoretical approach argues that co-dependency is a learned behaviour, the implication is that it can be unlearned. If you love your partner and want to keep the relationship, you need to heal yourself first and foremost.

We present here a few steps that such therapeutic approaches follow to heal a person from co-dependency:

1. Taking a start in being honest with him. Being honest in one's communication and in expressing their needs and desires.

2. Working upon negative thinking and errors in thinkings

3. Learn not to take things personally. It takes a lot of work for a co-dependent person not to take things personally, especially when in an intimate relationship. Accepting the other as they are without trying to fix or change them is the first step.

4. Putting in practice the process of socializing. There is nothing wrong with taking a break from your partner. It is healthy to have friendships outside of your partnership. Going out with friends brings us back to our centre, reminding us of who we really are.

5. Consider couple therapy or individual therapy. A therapist serves as an unbiased third party. They can point out co-dependent tendencies and actions between the two that the may not be aware of.

6. Rely on peer support. Co-Dependents Anonymous is a 12-step group similar to Alcoholics Anonymous that helps people who want to break free of their codependent behaviour patterns.

7. Establish boundaries. Those who struggle with co-dependency often have trouble with boundaries. We do not know where our needs begin or where the other's end. We often thrive off guilt and feel bad when we do not put the other first.

8. Self-Care programme. In a healthy relationship, both people have fully formed identities outside of their time together. They each bring unique attributes to the table - creating a partnership that allows both of them to grow and thrive. Watching a loved one struggle with drug or alcohol addiction is heart breaking, but they won't be in any position to support their partner's addiction treatment unless you make time to address your own mental health needs.

We shall take the example of co-dependency in intimate relationships. The signs and symptoms of love addiction include:

$\checkmark$ Always craving and searching for a romantic partner

$\checkmark$ Choosing a partner who is non-committal or emotionally unavailable

$\checkmark$ Trying to re-create the 'honeymoon' phase of a relationship and inability to maintain a relationship once this is phase is over

$\checkmark$ Constantly feeling desperate and afraid that a partner will leave

$\checkmark$ Choosing a romantic partner over family, friends, work, school, hobbies and interests

$\checkmark$ Compromising your values or beliefs in order to keep a significant other

$\checkmark$ When single, constantly using sex and fantasies as a means to avoid loneliness

$\checkmark$ Choosing partners who are abusive, demanding or require caretaking

Love Addiction can be cured. The first step is to address the major issue, that is the lack of love. Not a lack of love for others, but love for oneself. The first step to ending a toxic relationship starts with the self. Establishing a daily practice of self-love is key to being able to walk away from a relationship that is harming you. 
The following steps are suggested for healing co-dependency in intimate relationships in Kaminer's book [5]:

1. Getting Help for love addiction in a toxic relationship

Love addiction can get to the point where it requires professional help. Certified and highly trained clinical professionals help the person to get to the root cause of their addiction and create a treatment plan individually tailored to their needs. Through counselling, the provide the person with the tools necessary to engage in healthy relationships.

2. Avoid Relationship addiction by shifting the person's focus

Rather than obsessing about their relationship, the should begin to shift the focus to their self. Whether the person believe the kind words the person tell the himself or not, simply repeating certain mantras every day will have an effect on altering entrenched false beliefs and brain patterns that the person hold. Some messages of positive self-regard are: $I$ am a lovable and valuable person/ I deserve to be happy/I am capable/I am enough/I am worthy of love/I accept and love myself fully.

\section{Combat Co-dependency with Independence}

Love addiction is fraught with issues of co-dependency. If the person is struggling with shifting their focus to the themselves, a great way to achieve this is by finding areas in the person's life where the person can be independent from the partner. Some examples of being independent are: joining a fitness class or interest group, ensuring to have at least one night with friends a week or picking up a hobby that the person had left behind due to the relationship.

3. Be Prepared for Relationship Withdrawal

As with any addiction, if the person are addicted to a relationship, the person will experience withdrawal when the person decide to stop it. The physical symptoms of love addiction withdrawal are: nausea, insomnia, anxiety and depression.

The person can prepare for this by creating the proper supports before exiting the relationship. Supports can come in the form of friends and family or professional help. If the person put these supports in place beforehand the person will be better prepared for the inevitable withdrawal from the relationship.

\section{CONCLUSIONS}

The controversy around co-dependency is divided into two camps. At one end there are mental health professionals who advocate that co-dependency is a widespread and treatable disease. A major obstacle is the lack of consensus about the definition of codependency and diagnostic criteria. For insurance purposes, clinicians usually diagnose patients with anxiety or depression, which are symptoms of co-dependency.

Co-dependency is a big factor in addiction, and it can come from the person who is addicted or their partner. Co-dependency is an emotional and behavioural issue that causes a person to be incapable of having a mutually satisfying, healthy relationship. A co-dependent partner will stick by their partner suffering from addiction no matter how unhealthy the relationship is.

Relationships can be one of the major triggers in a person's addiction and they may not even realize it. Whether the relationship appears healthy or not, many people get stuck in the cycle of drinking or using as a way of managing their relationship. One of the biggest suggestions for anyone suffering from co-dependency is to get professional help and try not to get into a new relationship. It's important to understand unhealthy relationships, codependency, as well as the benefits of loving oneself in order to recover. 


\section{REFERENCES:}

1. Beattie, M. (1987). Codependent no more. San Francisco: HarperCollins.

2. Darlene Lancer, Codependency for Dummies, 2d. ed. John Wiley \& Sons, 2015

3. Greg E. Dear, et al. (2004). "Defining co-dependency: a thematic analysis of published definitions." In S. Shohov (Ed.), Advances in Psychology (Vol. 34, pp. 189-205). New York, NY: NovaScience Publishers

4. John Bradshaw, Healing the Shame that Binds The person, Health Communications, Inc., 2010.

5. Kaminer, W. (1992). I'm dysfunctional. The person're dysfunctional: The recovery movement and other self-help fashions. New York: Addison-Wesley

6. Kabakçi E.,Ançel G, Psychometric properties of the Turkish form of Codependency Assessment Tool., Arch Psychiatr Nurs. 2009 Dec;23(6):441-53. doi: 10.1016/j.apnu.2008.10.004; Internet source: https://www.ncbi.nlm.nih.gov/pubmed/19926026

7. Marina Milushyna,Foreign studies of the codependency phenomenon, Humanities and Social Sciences 2015,HSS, vol. XX, 22 (2/2015), April - June

8. Sharon Wegscheider-Cruse, Joseph Cruse, Understanding Codependency, Health Communications, Incorporated, 1990. 